\title{
THE SOCIOLOGICAL ANALYSIS OF SENSORY KNOWLEDGE: ITS UNDERSTANDING, CONSTRUCTION AND ACQUISITION
}

\author{
HONORATA JAKUBOWSKA ${ }^{1}$ \\ ${ }^{1}$ Adam Mickiewicz University in Poznań, Institute of Sociology, Szamarzewskiego 89 C, 60-568 Poznań, \\ Poland. ORCID: 0000-0002-5781-4297, Email: honorata@amu.edu.pl
}

\begin{abstract}
The aim of this article, based on the literature review, is to explore the senses within the context of knowledge. The article begins with a description of embodied (i.e., also sensory) knowledge's marginalisation within the social sciences and the reasons for this. After indicating the most popular fields of research, the article explores three main understandings of sensory knowledge: (1) senses as a source of knowledge, (2) senses as acquired skills and (3) sensory knowledge as a result of (collective) activity. In the next part, sensory knowledge is discussed as tacit knowledge, taking into account the problem of its verbalisation and the nature of its acquisition. The last part explores the social construction of sensory knowledge and its relation to subjective experiences, referring to the concepts of intersubjectivity, objectification and legitimisation.
\end{abstract}

KEYWORDS: senses, sensory knowledge, tacit knowledge, skills, objectification, social constructionism

At the end of the $20^{\text {th }}$ century and the beginning of the $21^{\text {st }}$ century, several turns occurred in the social sciences. One of them, the focus of this article, was the "sensory turn" (Howes 2006; Lahne 2018), which is marked by the questioning of optocentrism, accompanied by a growing interest in the other senses and an increasing number of studies and publications in this area. The sensory turn should be perceived within a wider context of changes within the social sciences, indicated by, among others, a high level of interest in the body (embodiment), emotions and space. There is no doubt that embodiment has a sensual nature as, due to the body, one can hear, touch and smell. Moreover, the perception of the environment and everyday spaces (e.g., home, shops, restaurants) has a multi-sensual nature that has been already noted by Edward T. Hall (1966). The author emphasized that our spatial experience is multisensory and 
information about the environment is received through senses. Moreover, he stated that people from different cultures organise and perceive space in different ways, they 'inhabit different sensory worlds.' (p. 2)

The aim of this article is to explore the senses within the context of knowledge. As noted by Maslen (2015), "the senses can be examined in terms of their contexts, acquisition processes, and applications, like any other knowledge source" (p. 52). Therefore, it is possible to speak about sensory knowledge, i.e., knowledge based on sensua experiences. The article is based on the literature review, which has highlighted the main fields of research, the main meanings of sensory knowledge that have been used so far and the process of sensory knowledge construction.

The article begins with a description of embodied (sensory) knowledge's marginalisation within the social sciences and the reasons for this. Then, the most popular areas of research are indicated. The following part provides the three meanings of sensory knowledge: (1) senses as a source of knowledge, (2) senses as acquired skills and (3) sensory knowledge as a result of (collective) activity. Next, sensory knowledge is presented as tacit knowledge, and, in the last part, the issues of sensory knowledge's intersubjectivity, objectivation and legitimisation are discussed. At the end of the article, a significant number of references are listed, which should be helpful for reader who are interested in developing their understanding of the analysed concept.

\section{MARGINALISATION OF EMBODIED KNOWLEDGE}

Sensory knowledge can be perceived as a part of embodied knowledge. Ethnographer Steven Feld (1996) stated that the ways of sensing and hearing the world are "internalized as bodily knowledge, part of the everyday 'body hexis' (Bourdieu 1977: 8), naturalized regime of 'body techniques”' (Mauss 1979 [1935]) (p. 100, cited after Rice 2010). Embodied knowledge can be understood as knowledge acquired through the body, the embodiment of particular skills that are learned due to practice, experience, observation and imitation. For a long time, this kind of knowledge has remained on the margins of sociological considerations and research, although knowledge itself has been an important topic in sociology. To a large extent, embodied knowledge has tacit nature (Polanyi 1966), which could be one of the reasons for its omission.

The social sciences have been dominated by a paradigm of social constructionism (Berger and Luckmann 1966). Constructivists assume that phenomena and objects do not exist until they appear in culture and manifest themselves through cultural products, including, above all, language. In this paradigm, knowledge is also a social construct, and the main role in its production and transmission is performed by acts of communication. Language itself is an object of transmission, but it is also a tool used to convey information about the reality around us (Schütz 1974 [1932]; Luckmann 1975; Knoblauch 2011). The status of nonverbal knowledge can be also influenced by the significance attributed to discourse, which is perceived as a basic tool for creating reality and a tool of power (e.g., the notion of knowledge-power proposed by Foucault 1975, 1976). The concepts related to the transmission and reproduction of knowledge often refer to its discursive dimension, which can be illustrated by the theory of repro- duction in education (Bourdieu and Passeron 1970) and the theory of language codes proposed by Basil Berstein (1990) ${ }^{1}$

In the last decade, one can observe, mainly in German social science, a communicative turn in the sociology of knowledge (Keller, Knoblauch, and Reichertz 2013), i.e., that "it started to focus on the forms, genres and patterns of communication in which knowledge is objectified, transmitted and appropriated" (Knoblauch, Jacobs, and Tuma 2014). This turn seems to emphasise the role of language and marginalise the role of the body in knowledge transmission. Indeed, initially, embodiment was neglected in the considerations of communication acts, as illustrated in Berger and Luckmann (1966), Habermans (1991) and (Knoblauch 2013). However, in the current analysis, the embodied character of communicative action has been taken into account. It is assumed that a communicative action not only has a verbal nature but also is incorporated and performed in a particular space and time; moreover, the performed action and its reception is related to the different senses (Knoblauch 2011, 2013; Knoblauch, Jacobs, and Tuma 2014).

Therefore, the role of the body has been included in the analysis of knowledge transmission to some extent; however, very few publications focus on it (Jakubowska 2017). It is even more difficult to find research on the role of the senses carried out in the field of sociology of knowledge. However, as noted at the beginning of the article, scientific interest in the senses is growing, also in the context of knowledge, which can be observed mainly in anthropology and, to a lesser extent, in sociology. Nonetheless, it seems that the worlds of the anthropology/sociology of the senses and the sociology of knowledge remain separated, although sensory studies could provide new insigh into the sociological analysis of knowledge. The following parts, based on the literature review, will present the main fields of sensory knowledge research and the main understanding of sensory knowledge.

\section{THE FIELDS OF SENSORY KNOWLEDGE RESEARCH}

The literature review has indicated the main fields in which the senses are analysed within the context of knowledge. It is worth noting that, although a significant number of authors (Serres 1985; Rodaway 1997; Howes 1991, 2005) emphasise the meaning of multi-sensual analysis, the vast majority of publications are focused on one sense only. Taking into account the long tradition of visual studies and a large number of publications within this area, the focus in this article is on studies related to the other senses.

The first sense considered is taste. One of the main topics related to this sense is knowledge about the taste of wine (Teil 2001; Bach 2004; Hennion and Teil 2004; Parr et al. 2010). In 2012, the issue of Rivista di Estetica was devoted to this topic, and one of the contributors was Steven Shapin, the author of several publications on the taste

${ }^{1}$ A description of the reasons for embodied knowledge's marginalisation has a superficial nature because this article does not aim to precisely analyse particular cognitive models or theoretical approaches. It is only a starting point for further considerations on sensory knowledge. 
of wine (e.g., Shapin 2012, 2016) Another interesting article titled "Knowledge, Wine, and Taste: What good is knowledge (in enjoying wine)?" was provided by Kent Bach a few years earlier (2004). Besides wine, knowledge about the taste of coffee has also been an analysed topic, although much rarer than wine. The chapter "Phenomenology of Coffee Tasting: Lessons in Practical Objectivity” from Kenneth Liberman's book (2013) is a good example. The taste of food (not beverages) has been nearly omitted in the analysis of sensory knowledge, with the exception of the articles written about French cheeses (Teil 1996; Rétiveau, Chambers, and Esteve 2005).

The second sense which has been widely analysed in the context of knowledge is hearing. The recently published book, Sonic Skills. Listening for Knowledge in Science, Medicine and Engineering (1920s-Present), by Karin Bijsterveld, provides not only a discussion on sonic skills but also a significant number of references on this topic Hearing as a source of knowledge has been analysed with reference to the medica field, specifically in relation to the stethoscope (e.g., Rice and Coltart 2006; Rice 2013 Gardner and Williams 2015; Maslen 2016), but also with reference to sound engineers' (Porcello 2004) and car mechanics' work (Krebs 2014).

The publications on the sense of smell seem to be fewer and concern mainly perfumes and cooking (Teil 1998, Latour 2004, Wathelet 2013). Finally, although one can observe a growing interest in the sense of touch in the social sciences (Montagu 1986; Classen 2005; Paterson 2007), it is rarely analysed as a source of knowledge. If it appears in this context, it is focused on medical diagnosis (e.g., Harris 2016).

Although, as mentioned above, the vast majority of publications are focused on one sense, there are also examples of articles based on a study of two interrelated senses in one activity - for example, touch and hearing in medicine (Harris 2016) or taste and smell in the wine industry (Parr et al. 2010). However, one can presume that the focus on isolated senses in research results more from empirical reasoning or the authors' scientific interests than the possibility of separating the senses in everyday practices.

The publications on sensory knowledge are concerned with several topics, regardless of which sense is their focus. The first topic is the role of the senses in diagnosis, in which sensory knowledge is analysed mainly in the medical context, but also with reference to other professions. In this context, the role of hearing and touching seems to be particularly important. The second topic is expert knowledge, which is obviously related to the previous one (only an expert can make a correct diagnosis); however, in this context, the attention is given mainly to such issues as the "intersubjectivity," "objectivity" or "standardisation" of taste, that is, how subjective and personal taste becomes recognisable knowledge. The third topic, also partially related to the first one, is the focus on the learning process - in other words, how a novice learns to hear, see or touch supported by an expert in a field. Unfortunately, a significant number of these publications have only a theoretical character and are based on a limited number of concepts. Finally, one can distinguish the autoethnographies, in which the authors analyse their own sensory experiences.

\section{RELATIONS BETWEEN SENSES AND KNOWLEDGE}

What is probably more important than the fields of research is an understanding of the senses within the context of knowledge. The literature review has highlighted three main conceptions; however, it should be noted that their distinction has an artificial nature and is used for the analytical purpose.

\section{Senses as a Source of Knowledge}

The first meaning of the senses relates to their perception as a source of knowledge. Initially, "seeing has been considered the dominant mode of knowledge acquisition" (Maslen 2015). After a critical approach towards the hierarchy of senses and the domination of sight (Classen 2005; Howes 2006), other senses, such as hearing and touch, also started to be considered as sources of knowledge. Therefore, seeing, hearing, touching, smelling and tasting have been perceived as a way of knowledge acquisition used both by laypersons and experts. For example, there is medical hearing (Rice and Coltart 2006; Rice 2013; Gardner and Williams 2015), diagnostic touching (Harris 2016) and coffee or wine tasting (Liberman 2013; Shapin 2012, 2016). Although, for example, in a medical context, "technologies are viewed as replacing the senses" (Harris 2016), their role is still important in many fields of social life, including medicine.

Besides the general term, "sensory knowledge," that is, knowledge acquired by the senses, one can find terms related to the particular senses. Some examples are "aural knowledge" (Maslen 2015) or "auditory knowledge” (Powis 2018), "seeing knowledge" (Collins and Evans 2007) and "haptic knowledge," which is divided into "proximal" and "distal" knowledge (Paterson 2009). David Howes, one of the key authors in the field of sensory studies, stated that "all of our organs of perception might to said to possess some form of knowledge" (2005: 28). Writing on the Cashinahua (ethnic group in Peru), he distinguished skin knowledge, hand knowledge, eye knowledge and ear knowledge. This means that knowledge is not only provided by verbal communication but also by sensual experiences, which are difficult to verbalise. By the sense of smell, one can know if the food is still fresh; by touch, one can discover some alarming changes in the body (e.g., breast tumour); while hearing can warn one of danger (e.g., an approaching train).

The senses are perceived not only as a source of knowledge about the environment and the world around us (Brulé and Bailly 2018) but also as a source of self-knowledge and self-perception (Maslen 2015; Harris 2016). The studies focused on this kind of knowledge are found especially in the field of sport. It is not surprising that researchers have drawn their attention to the role of the senses in sports practices since "sports participants hear, smell, see, touch and move within their particular sporting environments, whether hockey pitch, mountain face, ice rink or squash court" (Hockey and Allen-Collinson 2007: 123). The analysis of self-knowledge is based on autoethnographic studies, during which the researcher's body becomes the main "instrument" of sensual data collection (Sparkes 2016: 46). Other examples include the research of Hockey (2006), Allen-Collinson and Hockey (2011) and Sparkes (2009). 


\section{Senses as Acquired Skills}

The second understanding of the senses within the context of knowledge is their perception as acquired skills (more rarely, as competencies or abilities). Skills perceived in terms of knowledge are usually described as having a few particular features. First, they are learnt. Even if skills have, to some extent, a biological basis, they are developed through the process of learning. Second, the skills are related to achievements and goals. Third, skills development requires practice, which is the only way to become more proficient in them; however, practice alone cannot guarantee success. Fourth, bodily skills are not completely separate from intellectual and cognitive skills. Finally, one can talk about the history of a skill's life and its development over time; as a consequence, it is quite easy to distinguish a novice from an expert (Jakubowska 2017).

This perception of senses suggests that, although the vast majority of people can use all the senses in everyday life, their use can be developed to enable a person to hear, smell or see something that is unnoticed by a layperson. As noted by Carpenter (1973), "any sensory experience is partly skill and any skill can be cultivated" (p. 20). Olivier Wathelet, in his article, "Apprendre à voir" (Learn to see) (2012), described the process of skills learning using the example of seeing. As the author stated, one can learn to see and, as a consequence, transform vision into skilled vision and/or achieve virtuosity of vision. In this context, the term "vis-ability" is also relevant, as used by Schindler (2009: 135) to speak about the ability to analyse video recordings of the process of knowledge transmission during judo training sessions. A person who has experience in practising and/or learning this sport is able to see more than a person who is unfamiliar with it. The same ability can apply to the other senses as well.

Sensory skills allow a person not only to register a sound, a taste or a smell that is unrecognised by others, i.e., to notice hard-to-detect features, but also to distinguish similar qualities and discriminate more and more subtle differences. Some authors (e.g., Sutton 2006), in describing the different skills that are learnt, make reference to the concept of "education of attention" proposed by Ingold (2000). These learned skills have been analysed in the example of wine and perfumes (Teil 1998; Latour 2004; Bach 2004).

Skills transfer and acquisition are realised through body practices, in and through the body (Marchand 2008). Due to training and experience, skills become incorporated (Leder 1990; Ingold 2000: 5). Considering the acquisition of olfactory skills, Latour (2004) described the body as "learning to be affected" (p. 213), that is, the body is trained to sense and to be sensible. With practice, the senses become incorporated and perceived as embodied skills (e.g., taste as an embodied skill - Perullo 2012). An embodiment of sensory skills is also emphasised by the terms which refer to the experts in particular fields of social life. For example, a "nose" or an "expert nose" is used to describe perfume specialists (Latour 2004), and the terms "expert eye" and "expert ear" appear in the analysis of the work of car mechanics (Krebs 2014).

The sensory skills can be also analysed using Marcel Mauss' concept of "body techniques” (1973 [1935]). Mauss defined body techniques as "ways in which from society to society men know how to use their bodies" (1973 [1935]: 70). According to Howes
(1990), education related to the senses should be perceived as part of a process of body techniques transmission; therefore, it is possible to speak about "sensory techniques" or "perceptual techniques." This approach was used, for example, by Jonathan Sterne (2003, cited after Bijsterveld 2019), who wrote on the "audible technique."

The researchers are unanimous that the acquisition of sensory knowledge (skills) can be made only in practice, through a long training conducted by an expert (Ingold 2000; Harris and van Drie 2015; Bijsterveld 2019). This has been already noted by Michael Polanyi, the author of the concept of tacit knowledge:

Connoisseurship, like skill, can be communicated only by example, not by percept. To become an expert wine-taster, to acquire a knowledge of innumerable different blends of tea or to be trained as a medical diagnostician, you must go through along course of experience under the guidance of a master. (Polanyi 1958: 56)

\section{Sensory Knowledge as a Result of (Collective) Activity}

The third, less common perception of sensory knowledge refers to the process through which knowledge is acquired and constructed in the performance of activities. This approach has a lot in common with the perception of knowledge as communicative action, which was mentioned in the first part of the article. It also partly relates to understanding the senses as embodied skills, the acquisition of which requires practice, i.e., engaging in the same activities over a long time.

Gardner and Williams (2015), in their research on medical diagnosis, used the expressions "embodied sensing and acting" and "sensing and acting habits" to describe the physicians' bodies and their knowledge. This knowledge is acquired by activities but is also expressed by them; moreover, the senses play a significant role in these activities. Therefore, it is possible to analyse medical knowledge by the analysis of embodied actions and/or habits, which have a sensory nature.

What is specific in this approach is its focus on collective knowledge. The creation of knowledge by collective practices has been presented mainly within the context of taste. As noted by Hennion (2005):

Taste as an activity is accomplished through a collective which provides a frame, the relevance of the effort, and which guarantees results, accompanies, guides, puts into words. (p. 135)

The collective process of sensory knowledge creation takes place, for example, during the culinary contests of wine or coffee, which have been analysed (Teil and Hennion 2004; Shapin 2012; Liberman 2013). Although everyone can have a different taste and perceive a particular drink in a different, subjective way, there is also a process during which the notes have to be assigned and the best taste has to be chosen This process usually has a collective character (e.g., when the experts in a field engage in discussions towards making a common decision) and is related to sensory knowledge objectification, which will be discussed later. 


\section{SENSORY KNOWLEDGE AS TACIT KNOWLEDGE}

Although sensory feelings play an important role in the different areas of everyday life, their verbalisation remains a challenge, both for the person who wants to express these feelings and for the researchers who are interested in studying sensual feelings and experiences. In this regard, one can say that sensory knowledge remains, at least to some extent, tacit (Polanyi 1966).

The concept of tacit knowledge was introduced by Michael Polanyi, who stated that "we can know more than we can tell" (1966: 4). According to the author, one has the ability to perform a practical task, e.g., ride a bike or hammer a nail, but, at the same time, has difficulty in precisely defining and verbalising this "know how." Neil Gascoigne and Tim Thornton (2013) discussed Polanyi's statement that "tacit knowledge is untellable" and claimed that tacit knowledge can be expressed verbally; however, it will be understood only in a particular situation or context ${ }^{2}$.

Tacit knowledge is seen as practical knowledge related to skills and abilities which are developed through exercises and practice. Harry Collins (2010) delineated three kinds of tacit knowledge: (1) relational, (2) somatic and (3) collective. Relational tacit knowledge can be made explicit to the largest extent; however, it remains deliberately tacit in certain situations, such as when a group of experts do not want to share specialist knowledge. Somatic tacit knowledge can be understood in terms of Polanyi's concept. Collective tacit knowledge is related to the social community and "the way society is constituted" (Collins 2010, p. 85), and it is acquired via the interactions in the framework of a particular community.

The tacit character of sensory knowledge has been emphasised by a number of authors (e.g., Harris and van Drie 2015; Bijsterveld 2019). Two aspects seem to be pivotal here: the way of acquiring sensory knowledge and the problem of verbalising this knowledge. Sensory knowledge is transmitted in practice, within an apprenticeship context, due to the interactions between an expert (a master) and a novice. At the same time, this process of professional development can be seen as collective tacit knowledge, as distinguished by Collins (2010). On the one hand, it is based on the interactions, while, on the other hand, it obliges the novice to adapt to the existing knowledge within a particular community. For example, a person who has learnt cooking alone at home, but starts to cook in a restaurant, could be obliged to learn different ways of cooking which are the norms of this particular setting.

The second feature of sensory knowledge perceived as tacit knowledge is the problem of its articulation or verbalisation, which has been raised by several authors (e.g., Teil 1998; Bach 2004). It seems relatively easy to tell someone about what one has seen in order to be understood by the other person. On the other hand, it is much more difficult to describe smells, sounds or tactile sensations. In particular, tactile or taste experiences, contrary to visual experiences, seem to be more subjective. Geneviève Teil (1998), in her writings about smell, emphasised that smelling is an individualised experience, based largely on individual and collective memory and physiology. Acous- tic or scented impressions cannot be "seen" and, as a result, it is very difficult to talk about them and convey their essence.

Therefore, everyday sensory knowledge remains tacit to a large extent. For this reason, becoming an expert requires not only particular sensual skills but also the acquisition of "sensory language." A wine enthusiast can evaluate a particular wine as good (or bad), strong, etc., while a wine expert should be able to classify wine and describe it according to the established categories (Teil 1998). The same applies to other sensory experts, such as flavourists, perfumers (Agapakis and Tolaas, 2012: 570) and physicians. As noted by Harris (2016), "medical students need to be trained to match sensations to words and types” (p. 44).

The difference between a novice and an expert can be observed to the extent to which their knowledge remains tacit. An expert will be able to verbalise more sensory experiences than a layperson. Moreover, proficiency in a specialised language and association within a narrow circle of experts can contribute to a growing content of relational tacit knowledge, which will remain, to a large extent, inaccessible to laypersons.

\section{SENSORY PERCEPTION: FROM SUBJECTIVITY TO OBJECTIFICATION}

The verbalisation of sensory knowledge is considered not only in relation to tacit knowledge but also in the context of knowledge objectification. Language, as the main tool of communicative objectification (Schutz 1974 [1932]; Habermas 1981), allows the transforming of subjective sensual experiences and meanings into "objective" knowledge. However, as noted by Knoublauch (2013), not only language but also things, such as the flavour of wine or the tactile perceptions of a deaf and blind person, can be considered as objectification. From this perspective, sensory knowledge is a part of socially constructed knowledge and reality (Berger and Luckmann 1966).

This has been emphasised by Kenneth Liberman (2013), who, in his writing about coffee tasting, distinguished two kinds of objectivity:

The first is the real objectivity that is the actually existing taste of some coffee this is the objectivity that always has some subjectivity attached to it. There is another sense of objectivity that is a socially constituted objectivity, more abstract and less immanent, and which seeks to remove all traces of subjective experience. This objectivity doesn't just happen-it is socially constructed and therefore is an artefact. (p. 222)

The main terms used to speak about this process are objectification, mentioned above, and intersubjectivity, the understanding of which is provided, for example, by Steven Shapin (2012), in his article on the taste of wine. According to the author, intersubjectivity can be understood as:

The ability of a group of people reliably to assign the same word to the same private olfactory or gustatory experience, and, therefore, to agree that they share subjective states. (p. 82)

It seems that both terms, objectification and intersubjectivity, are used as synonyms by the authors writing on the senses and knowledge. Both notions emphasise 
the collective nature of the practice, the attempt to eliminate individual subjective experiences and the crucial role of language.

Shapin (2012) indicated two main ways of making sensory knowledge objective. The first is "the vast expansion of putatively referential descriptors (peach skin, wet stones, fig paste)" (p. 75). The second is based on quantitative systems of evaluation. Using the first method, people refer to the taste, smell or sound that they have already known, and they also reach out to metaphors and/or onomatopoeia (Bijsterveld 2019). In the case of sound, the same linguistic tools have been also observed in the acquisition of sports skills (Jakubowska 2017). This practice partially results, as one can suppose, from the tacit nature of sensory knowledge. It is difficult to precisely explain gustatory, olfactory or tactile feelings; therefore, different linguistic tools are helpful to express these experiences and construct common knowledge.

The second method, quantitative evaluation, is used by professionals and experts, mainly in gastronomy, e.g., in the case of wine, coffee and restaurants (Shapin 2012 Liberman 2013) The different types of wine evaluations and their history can be found in Shapin's article (2012). Quantitative evaluation is based on numerical scores or stars, which are used, for example, in the case of restaurant reviews, and the author called this process "scoring subjectivity."

Maybard Amerine (1983 [1976]) proposed the term "the sensory evaluation of wines" as distinguished from "the sensory enjoyment of wines." During the latter practice, shared by wine enthusiasts, subjective experiences (may) play an important role in sensory evaluation, and subjectivity should be disciplined or eliminated (Shapin 2012: 78). It is also worth mentioning the distinction between the descriptive and normative nature of wine, identified by Nicola Perullo (2012). As the author explained, "the first approach describes things as they are, the second as they should be" (p. 7).

There are a number of similarities between the sensory evaluations of wine and coffee. In describing the coffee market, Kenneth Liberman (2013) stated that there is no doubt that drinking coffee is a subjective experience; however, also objective knowledge, including standard terminologies, on "the perfect cup of coffee" have been created to satisfy clients and consumers.

In addition, both in the process of sensory skills acquisition and sensory evaluation, different tools are used. For example, there are perfume (odour) kits (Latour 2004) and the "wine aroma wheel" (Todd 2012; Shapin 2016). Their aim is to allow a person to name their own sensual experiences by using already existing terminology and to communicate with others; that is, they simplify the objectification of sensory knowledge.

Although the analysis of sensory knowledge objectification is mainly focused on taste and smell, the same process can be observed with reference to the other sens es. For example, listening to music at home or during a concert can be perceived as "sensory enjoyment." However, during music contests, such as for piano or violin, the sound becomes an object of sensory evaluation. Touch also can be an enjoyment (e.g., a massage given by a partner or by a specialist), but in physiotherapy, it will be evaluated in terms of its technical value.

Therefore, on the one hand, one can talk about the perception of senses and, on the other hand, about the judgement of senses. In the first approach, sense can, but does not have to be, considered in the context of knowledge. One can enjoy wine or coffe without having knowledge of what should be the taste of a particular type of wine or coffee. However, due to experience in tasting, one can become familiar with these products and their features and thereby gain more knowledge of them. The judgement of senses is perceived in a different way. Its aim is to create objective knowledge of the senses, in other words, to define what a good taste or appropriate smell is. These judgements are made by experts and professionals in a particular field, who establish "standards," which are later adopted by laypersons as objective knowledge. Individual experiences and judgements are not made in a "social vacuum," as noted by Perullo (2012), who stated, "[...] taste as knowledge is based on pre-existing social and inter-subjective codes that constitute the context in which we operate” (p. 18) The learning process, at least in the beginning, requires the acceptance of some suggestions and recommendations provided by experts, perceiving them as authorities whose knowledge is reliable.

The issue of the reliability of knowledge is particularly important in the areas of social life, where the role of the senses is crucial in decision-making that influences our health and even our life. For example, medical diagnosis and treatment based on the senses should be indicated. Although, as mentioned earlier, the human senses are, to a large extent, being supported or replaced by technologies, their meaning in medicine still remains crucial. The physicians listen to the heart beating or the lungs breathing, touch a stomach, look at the results of ultrasonography, and so on. Using the senses as a source of knowledge in this way, they make decisions as to a patient's treatment. Therefore, one can observe here professional jurisdiction about sensory knowledge (Bijsterveld 2019) and, at the same time, the legitimacy of the senses as (a source of) knowledge.

\section{CONCLUSION}

This article aimed to explore the sociological (and anthropological) analysis of senses within the context of knowledge. Due to limited space, the article could only indicate the main issues related to sensory knowledge that have appeared in the conducted literature review. There is no doubt that these issues can and should be developed much further. Therefore, the article should be treated as a short review of what has been done so far and a starting point for further exploration.

The division of sociology into multiple subdisciplines has led to a situation where scientific knowledge remains limited to the particular fields and does not exceed their boundaries. Meanwhile, the sensory studies can provide new and interesting insight into the sociological analysis of knowledge. The focus on different senses and embodiment can challenge, at least to some extent, the domination of verbocentrism and ocularcentrism and will be important in taking into account the multi-sensual nature of human experience.

Considering sensory knowledge as tacit knowledge, it should also be noted that deriving the appropriate methodology for this type of research still remains a challenge 
for sociologists and other researchers in the social sciences. Nevertheless, it is important to take up the challenge of delineating the meaning and significance of sensory knowledge in everyday life. This will require the further development of the social sciences and the collaboration between the different subdisciplines.

FUNDING: This research received no external funding.

CONFLICTS OF INTEREST: The author declares no conflict of interest.

\section{REFERENCES}

Agapakis, Christina and Sissel Tolaas. 2012. "Smelling in multiple dimensions." Current Opinion in Chemical Biology 16: 569-575.

Allen-Collinson, Jacquelyn and John Hockey. 2011. "Feeling the way: Notes towards a haptic phenomenology of distance running and scuba diving." International Review for the Sociology of Sport 46: 330-345.

Amerine, Maynard and Edward B. Roessler. 1983[1976]. Wines: Their Sensory Evaluation, rev. ed. New York: W.H. Freeman.

Bach, Kent. 2004. Knowledge, Wine and Taste: What good is knowledge (in enjoying wine)? Philosophy and Wine: from science to subjectivity. 10th December 2004, Senate House, University of London

Berger, Peter L. and Thomas Luckmann. 1966. The Social Construction of Reality. New York: Free Press.

Bernstein, Basil. 1990. The Structuring of Pedagogic Discourse: volume IV, class, codes and control. London: Routledge.

Bijsterveld, Karin. 2019. Sonic Skills. Listening for Knowledge in Science, Medicine and Engineering (1920s-Present). London: Palgrave Macmillan.

Bourdieu, Pierre. 1977. Outline of a theory of practice. Cambridge: University Press.

Bourdieu, Pierre and Jean-Claude Passeron. 1970. La Reproduction. Éléments pour une théorie du système d'enseignement. Paris: Minuit.

Brulé, Emeline and Gilles Bailly. 2018. "Taking into Account Sensory Knowledge: The Case of Geo-technologies for Children with Visual Impairments.” ACM CHI'18, Apr 2018, Montreal, Canada. doi: 10.1145/3173574.3173810

Carpenter, Edmund. 1973. Oh, What a Blow That Phantom Gave Me! New York: Holt, Rinehart and Winston.

Classen, Constance, ed. 2005. The Book of Touch. Oxford: Berg Publishers.

Collins, Harry. 2010. Tacit and Explicit Knowledge. Chicago: University of Chicago Press.

Collins, Harry and Robert Evans. 2007. Rethinking expertise. Chicago: The University of Chicago Press.

Feld, Steven 1996. "Waterfalls of song: an acoustemology of place resounding in Bosavi, Papua New Guinea.” Pp. 91-135 in Senses of place, edited by S. Feld \& K.H. Basso. Santa Fe: School of American Research Press.

Foucault, Michel. 1975. Surveiller et punir. Paris: Gallimard.

Foucault, Michel. 1976. Histoire de la sexualité. Vol I: La Volonté de savoir. Paris: Galli- mard.

Gardner, John and Claire Williams. 2015. "Corporeal diagnosis work and diagnosis spaces: Clinicians' use of space and bodies during diagnosis.” Sociology of Health and Illness 37(5): 765-781.

Gascoigne, Neil and Tim Thornton. 2013. Tacit Knowledge. Durham: Acumen

Habermas, Jürgen. 1981. Theorie des kommunikativen Handelns. Frankfurt, Germany: Suhrkamp.

Hall, Edward T. 1966. The Hidden Dimension. New York: Random House.

Harris, Anna. 2016. "Listening-touch, Affect and the Crafting of Medical Bodies through Percussion.” Body \& Society 22(1): 31-61.

Harris, Anna and Melissa Van Drie. 2015. "Sharing sound: teaching, learning, and researching sonic skills.” Sound Studies 1(1): 98-117.

Hennion, Antoine and Geneviève Teil. 2004. "Le goût du vin. Pour une sociologie de l'attention." Pp. 111-126 in Le goût de belles choses. Ethonologie de la relation esthétique, edited by V. Nahoum-Grappe and V. Odile. Paris: Edition de la Maison des sciences de l'homme.

Hennion, Antoine. 2005. "Pragmatics of Taste.” Pp. 131-144 in The Blackwell Companion to the Sociology of Culture, edited by M. Jacobs and N. Hanrahan. Oxford: Blackwell.

Hockey, John. 2006. "Sensing the run: The senses and distance running." Senses and Society 1(2): 183-202.

Hockey, John and Jacquelyn Allen-Collinson. 2007. "Grasping the phenomenology of sporting Dobies.” International Review for the Sociology of Sport 42(2): 115-131.

Howes, David. 1990. “Les techniques des sens.” Anthropologie et Société 14(2): 99-115.

Howes, David, ed. 1991. The Varieties of Sensory Experience. Toronto: University of Toronto Press.

Howes, David, ed. 2005. Empire of the Senses: The Sensual Culture Reader. Oxford \& New York: Berg.

Howes, David. 2005. “Skinscapes. Embodiment, Culture and Environment.” Pp. 27-39 in The Book of Touch, edited by C. Classen. Oxford: Berg Publishers.

Howes, David. 2006. “Charting the Sensorial Revolution.” Senses and Society 1(1): 113128

Ingold, Tim. 2000. The Perception of the Environment: Essays on Livelihood, Dwelling and Skill. London: Routledge.

Jakubowska, Honorata. 2017. Skill Transmission, Sport and Tacit Knowledge. A Sociological Perspective. Abington: Routledge.

Keller, Reiner, Hubert Knoblauch and Jo Reichertz, ed. 2013. Kommunikativer Konstruktivismus. Theoretische und empirische Arbeiten zu einem neuen wissenssoziologischen Ansatz. Wiesbaden: Springer/VS.

Knoblauch, Hubert. 2011. "Relativism, Meaning and the New Sociology of Knowledge." Pp. 131-156 in The Problem of Relativism in the Sociology of (Scientific) Knowledge, edited by R. Schantz and M. Seidel. Frankfurt: Ontos Verlag.

Knoblauch, Hubert. 2013. "Communication Perspective and Mediatization." Communication Theory 23: 297-315. 
Knoblauch, Hubert, Mark D. Jacobs and René Tuma. 2014. "Introduction: Culture, Communication, and Creativity.” Pp. 7-21 in Culture, Communication, and Creativity. Reframing the Relations of Media, Knowledge, and Innovation in Society, edited by H. Knoblauch, R. Tuma and M.D. Jacobs. Frankfurt, Bern, Brussels, New York, Oxford, Warschau, Wien: Peter Lang.

Krebs, Stefan. 2014. "Dial Gauge versus Sense 1-0”: German Car Mechanics and the Introduction of New Diagnostic Equipment, 1950-1980.” Technology and Culture 55(2): 354-389.

Lahne, Jacob. 2018. "Standard sensations: the production of objective experience from industrial technique." The Senses and Society 13(1): 6-18.

Latour, Bruno. 2004. "How to Talk About the Body? The Normative Dimension of Science Studies.” Body and Society 10(2-3): 205-229.

Leder, Drew. 1990. The Absent Body, Chicago: University of Chicago Press.

Liberman, Kenneth. 2013. "The Phenomenology of Coffee Tasting: Lessons in Practical Objectivity.” Pp. 215-266 In More studies in Ethnomethodology, by K. Liberman. New York: Suny Press.

Luckmann, Thomas. 1975. The sociology of language. Indianapolis: Bobbs Merrill.

Marchand, Trevor H.J., 2008. "Muscles, moral and mind: Craft apprenticeship and the formation of person." British Journal of Educational Studies 56(3): 245-271.

Maslen, Sarah. 2015. "Researching the Senses as Knowledge." The Senses and Society 10(1): 52-70.

Mauss, Marcel. 1979[1935]. “Body techniques.” Pp. 95-123 in Sociology and psychology: essays, by M. Mauss. London: Routledge \& Kegan Paul.

Montagu, Ashley. 1986. Touching. The Human Significance of the Skin. 3rd ed. New York: Harper and Row.

Parr, Wendy, Dominique Valentin, James A. Green and Catherine Dacremont. 2010. "Evaluation of French and New Zealand Sauvignon wines by experienced French wine assessors." Food Quality and Preference 21(1): 56-64.

Paterson, Mark. 2007. The Senses of Touch. Haptics, Affects and Technologies. Oxford, New York: Berg.

Paterson, Mark. 2009. “Haptic geographies: ethnography, haptic knowledges and sensuous dispositions.” Progress in Human Geography 33(6): 766-788.

Perullo, Nicola. 2012. “Wineworld: Tasting, Making, Drinking, Being.” Rivista di Estetica 3: 3-48.

Polanyi, Michael. 1958. Personal Knowledge. Chicago: University of Chicago Press.

Polanyi, Michael. 1966. The Tacit Dimension. Chicago: University of Chicago Press.

Porcello, Thomas. 2004. "Speaking of Sound: Language and the Professionalization of Sound Recording Engineers." Social Studies of Science 34(5): 733-758.

Powis, Ben. 2018. "Visual impairment, sport and somatic work: the auditory experiences of blind and partially sighted cricket players." The Senses and Society 13(2): 147-162.

Rétiveau, Annlyse, Delores H. Chambers and Emilien Esteve. 2005. "Developing a lexicon for the flavour description of French cheeses." Food Quality and Preferences 16(6): 517-527.
Rice, Tom. 2010. "Learning to listen: auscultation and the transmission of auditory knowledge." Journal of the Royal Anthropological Institute 16: 41-61.

Rice, Tom. 2013. Hearing and the Hospital: Sound, Listening, Knowledge and Experience. Canon Pyon: Sean Kingston Publishing.

Rice, Tom and John Coltart. 2006. "Getting a Sense of Listening: An Anthropological Perspective on Auscultation.” The British Journal of Cardiology 13(1): 56-57.

Rodaway, Paul. 1997. Sensuous Geographies. London \& New York: Routledge.

Schindler, Lisa. 2009. “The production of <<vis-ability >>: An ethnographic video analysis of a martial arts class.” Pp. 135-154 in Video Interaction Analysis: Methods and Methodology, edited by U. Kissmann. Peter Lang, Frankfurt am Main.

Schütz, Alfred. 1974[1932]. The phenomenology of the social world. Evanston, IL: Northwestern University Press.

Serres, Michel. 1985. Les cinq Sens. Paris: Grasset.

Shapin, Steven. 2012. "The Tastes of Wine: Towards a cultural history". Rivista di Estetica 3: 49-94.

Shapin, Steven. 2016. "A taste of science: Making the subjective objective in the California wine world." Social Studies of Science 46(3): 436-460.

Sparkes, Andrew C. 2009. "Ethnography and the senses: Challenges and possibilities." Qualitative Research in Sport, Exercise and Health 1: 21-35.

Sparkes, Andrew C. 2016. "Ethnography as a sensual way of being: Methodological and representational challenges.” Pp. 45-58 in Ethnographies in Sport and Exercise Research, edited by G. Molnar and L.G. Purdy. Abingdon: Routledge.

Sterne, Jonathan. 2003. The Audible Past: Cultural Origins of Sound Reproduction. Durham: Duke University Press.

Sutton, David. 2006. “Cooking Skills, the Senses, and Memory: The Fate of Practical Knowledge.” Pp. 87-118. in Sensible Objects. Colonialism, Museum and Material Culture, edited by E. Edwards, Ch. Gosden and Ruth B. Phillips. Oxford, New York: Berg.

Teil, Geneviève. 1996. "Dire le goût : expression experte et naïve à propos du goût des fromages.” Revue Francaise du Marketing 156: 65-77.

Teil, Geneviève 1998. "Devenir expert aromaticien: Y a-t-il une place pour le goût dans les goûts alimentaires ?” Sociologie du travail 40: 503-522.

Teil, Geneviève. 2001. "La production du jugement esthétique sur les vins par la critique vinicole." Sociologie du Travail 43(1): 67-89.

Teil Geneviève and Antoine Hennion. 2004. "Discovering quality or performing taste? A sociology of the amateur." Pp. 19-37 in Qualities of Food, edited by M. Harvey, A. McMeekin and A. Warde. Manchester: Manchester University Press.

Todd, Cain. 2012. "Expression and objectivity in the case of wine. Defending the aesthetic terroir of tastes and smells." Rivista diEstetica 3: 96-116.

Wathelet, Olivier. 2012. "Apprendre à voir. Pour une ethnographie cognitive des perceptions.” Revue francaise d'anthropologie 201: 121-130.

Wathelet, Olivier. 2013. "Un exemple d'ethnographie cognitive des perceptions : les cheminements perceptifs de l'activité culinaire.” Pp. 145-175. in Ethnograpier les sens, edited by P. L. Colon. Paris: Petra. 


\section{BIOGRAPHICAL NOTE}

Honorata Jakubowska is professor of sociology at the Adam Mickiewicz University in Poznań, Poland.

OPEN ACCESS: This article is distributed under the terms of the Creative Commons Attribution Noncommercial License (CC BY-NC 4.0) which permits any noncommercial use, and reproduction in any medium, provided the original author(s) and source are credited. 